Article

\title{
Rehabilitative Ultrasound Imaging Features of the Abdominal Wall Muscles in Elite and Amateur Basketball Players
}

\author{
Carlos Romero-Morales ${ }^{1}$ (D), Jaime Almazán-Polo 1,2,3, David Rodríguez-Sanz ${ }^{1,3}$, \\ Patricia Palomo-López 4 (iD), Daniel López-López ${ }^{2, *(1)}$, Sergio Vázquez-González ${ }^{1,3}$ \\ and César Calvo-Lobo ${ }^{5}$ \\ 1 Faculty of Sport Sciences, Universidad Europea de Madrid, Villaviciosa de Odón, 28690 Madrid, Spain; \\ carlos.romero@universidadeuropea.es (C.R.-M.); jaime.almazanpolo@gmail.com (J.A.-P.); \\ davidrodriguezsanz@gmail.com (D.R.-S.); sergio.vazquez@universidadeuropea.es (S.V.-G.) \\ 2 Research, Health and Podiatry Unit, Department of Health Sciences, Faculty of Nursing and Podiatry, \\ Universidade da Coruña, 15403 Ferrol, Spain \\ 3 Premiummadrid Global Health Care, 28040 Madrid, Spain \\ 4 University Center of Plasencia, University of Extremadura, 10600 Plasencia, Cáceres, Spain; \\ patibiom@unex.es \\ 5 Nursing and Physical Therapy Department, Institute of Biomedicine (IBIOMED), Universidad de León, \\ Ponferrada, 24071 León, Spain; ccall@unileon.es \\ * Correspondence: daniellopez@udc.es; Tel.: +34-981-16-70-00 (ext. 3546)
}

Received: 9 April 2018; Accepted: 14 May 2018; Published: 17 May 2018

\begin{abstract}
The aim of the present study was to evaluate and compare with rehabilitative ultrasound imaging (RUSI) abdominal wall muscle thickness and interrecti distance (IRD) between elite and amateur basketball players. A sample of 32 basketball players (age: $23.0 \pm 8.5$; height: $1.89 \pm 14.25$ m; weight: $86.6 \pm 15.5 \mathrm{~kg}$; body mass index: $22.8 \pm 2.6 \mathrm{~kg} / \mathrm{m}^{2}$ ) was divided in two groups: professional elite and amateur players. A diagnostic ultrasound tool with a 7-14 MHz range linear transducer was used for B mode ultrasound imaging. Ultrasound images of the external oblique (EO), internal oblique (IO), transversus abdominis $(\mathrm{Tr} A b)$, and rectus anterior (RA) muscles as well as IRD were measured and analyzed by ImageJ software. Statistically significant differences $(p<0.05)$ with greater height, weight, and Nijmegen scores were shown in favor of the elite basketball players compared to the amateur basketball players. Ultrasound measurements of the abdominal wall muscles showed statistically significant differences $(p<0.05)$ for increased IRD and left $\operatorname{Tr} A b$ thickness and decreased right and left EO thickness in favor of the elite versus amateur basketball players. The rest of the measurements did not show any statistically significant differences $(p>0.05)$. Increased IRD and $\mathrm{Tr} \mathrm{Ab}$ thickness and reduced EO thickness may be shown in elite versus amateur basketball players.
\end{abstract}

Keywords: abdominal muscles; basketball; diagnostic imaging; ultrasonography

\section{Introduction}

Rehabilitative ultrasound imaging (RUSI) has been used to evaluate the thickness, cross-sectional area (CSA), and connective tissue associated with musculoskeletal features that may influence physical therapy evaluation [1]. Furthermore, RUSI has been widely used to assess motor control and function [2].

Considering the upper limb, supraspinatus muscle thickness has been associated with subacromial impingement syndrome [3]. Ultrasound may be considered as a valid and reliable technique to assess the CSA of intrinsic hand muscles and could be useful to predict muscle strength in patients with nerve 
injuries [4]. Regarding the lower limb, a recent study found decreased thickness in the vastus medialis muscle in patients with knee osteoarthritis [5]. Additionally, peroneus longus CSA was reduced in patients with lateral ankle sprains compared with patients without this condition [6]. CSA and thickness of the abductor hallucis and flexor hallucis brevis were reduced in patients with hallux valgus [7]. With respect to the temporomandibular region, the function of the masseter, temporalis, and sternocleidomastoid muscles has been linked with temporomandibular joint disorders [8]. Javanshir et al. $[9,10]$ showed that monitoring deep cervical flexor muscles with ultrasonography may be carried out during training programs for patients with chronic neck pain. In the trunk region, multifidus and abdominal wall muscles have been related to lumbopelvic pain (LPP) [11,12].

Muscles of the abdominal wall act to support and provide stability to the spine [13]. These muscles form a ring surrounding the spine, with the rectus abdominis (RA) in the midline and laterally three overlapping layers comprising the external oblique (EO), internal oblique (IO), and transversus abdominis (TrAb) [12]. These muscles work in a coordinated system in conjunction with the diaphragm, lumbar multifidus, and pelvic floor muscles to transfer loads around the trunk and balance abdominal pressure [13]. In patients without LPP, RA, OI, OE, and $\operatorname{TrAb}$ represent $35.0 \%, 28.4 \%, 22.8 \%$, and $13.8 \%$ of cumulative abdominal thickness, respectively [14]. Moreover, Whittaker et al. [12] found thinner RA and thicker perimuscular vertebral connective tissue in individuals with LPP. All these measures may be very useful to assess muscle changes that could exist with pathology [15]. Excellent interexaminer reliability (intraclass correlation coefficient $(I C C)=0.92-0.99$ ) has been shown for RUSI thickness measurements of abdominal wall muscles [12]. The relationship between abdominal wall muscle thickness measured with magnetic resonance imaging (MRI) and RUSI showed appropriate validity (ICC $=0.84-0.95)[15,16]$. The inherent variability of the measurement location and the respective change in RUSI thickness measurement of the abdominal wall have shown a standard error of measurement (SEM) of 0.2-0.4 mm and a minimum detectable change (MDC) of 0.6-1.1 mm [12].

Different assessment tools, including magnetic resonance [17], electromyography [18-20], and RUSI, may be used to evaluate the morphology and characteristics of the abdominal wall muscles. RUSI may be considered as a noninvasive, relatively inexpensive, and portable technique that provides a complete evaluation of the morphology and size of muscle tissue [12].

Finally, RUSI assessments were performed at rest in order to study muscular tissue thickness (ICC $=0.98-0.99)$ and interrecti distance (IRD) $($ ICC $=0.99)$ of the abdominal wall under LPP conditions [12]. In addition, ultrasonography evaluation of the abdominal and trunk muscles may predict the risk of injury in professional football players [21]. Asymmetry of IO thickness may play a protective role against injury development in cricket pace bowlers, while reduced TrAb thickness during activation of the dominant side may show a greater risk of injury in these players [22]. Nevertheless, there is a lack of studies addressing abdominal wall morphology among athletes at different levels of play, and RUSI comparison of the abdominal wall muscle tissue of elite and amateur basketball players has not been carried out. Therefore, the aim of the present study was to evaluate and compare with RUSI the thickness and IRD of abdominal wall muscles (EO, IO, TrAb, and RA) between elite and amateur basketball players.

\section{Methods}

\subsection{Study Design}

A cross-sectional observational study was performed from January to March 2018, following the Strengthening the Reporting of Observational Studies in Epidemiology (STROBE) guidelines [23].

\subsection{Sample Size Calculation}

A sample size calculation was carried out by the difference between 2 independent groups with $\mathrm{G}^{*}$ Power 3.1.9.2 software and based on the IR distance $(\mathrm{cm})$ of a pilot study $(n=20)$ with 2 groups (mean $\pm \mathrm{SD})$ : 10 elite basketball players $(1.7 \pm 0.8 \mathrm{~cm})$ and 10 amateur basketball players $(1.1 \pm 0.3 \mathrm{~cm})$. For the sample size calculation, 1-tailed hypothesis, an effect size of 0.99 , an $\alpha$ error probability of 0.05 , a power 
(1- $\beta$ error probability) of 0.80 , and an allocation ratio (N2/N1) of 1 were utilized. Therefore, a total sample size of 28 subjects, 14 for each group, was calculated. Considering $15 \%$ of possible participants lost to follow-up, a total sample of 32 subjects, 16 in each group, was considered.

\subsection{Participants}

A sample of 32 healthy basketball players (age: $23.0 \pm 8.5 \mathrm{y}$; height: $1.89 \pm 14.25 \mathrm{~m}$; weight: $86.6 \pm 15.5 \mathrm{~kg}$; body mass index (BMI): $22.8 \pm 2.6 \mathrm{~kg} / \mathrm{m}^{2}$ ) was recruited and divided in 2 groups: professional elite basketball players from the Spanish first division league club $(n=16)$ and amateur basketball players from an amateur Spanish division $(n=16)$. Professional elite basketball players followed a training schedule for $3 \mathrm{~h}$ each day, 6 days per week and played 2 matches per week. Amateur basketball players carried out a training schedule for $2 \mathrm{~h}$ a day, 1 day per week and played 1 match per week. Participant inclusion criteria were age 18 to 35 years; male sex; right-hand dominance, right-handed throw, and left-foot jump dominance. In addition, the professional group had to meet at least 3 of the following requirements: (a) at least 3 years as a professional player, (b) playing at least 1 year on the national team, (c) in youth categories, (d) won an international championship with his team or national team. Exclusion criteria were BMI greater than $31 \mathrm{~kg} / \mathrm{m}^{2}$, any musculoskeletal condition in the lumbopelvic region [12], hypocapnia [24], skin diseases, and lower limb pathology (i.e., fracture, surgery, osteoarthritis) [12]. For this study, if Nijmegen questionnaire score was higher than 24, the presence of hypocapnia was considered [25].

\subsection{Ethical Considerations}

The study was approved by A Coruña University Ethics Committee, Spain, and participants signed the informed consent form. The study also adhered to the ethical standards of the Declaration of Helsinki for human experimentation [26].

\subsection{Sociodemographic and Respiratory Distress Data}

Sociodemographic data such as age $(\mathrm{y})$, height $(\mathrm{m})$, weight $(\mathrm{kg})$, and BMI $\left(\mathrm{kg} / \mathrm{m}^{2}\right)$ were recorded. According to the methodology of a prior study that evaluated RUSI measurements of the abdominal wall [12], the Nijmegen questionnaire was registered in order to measure respiratory distress scores due to their relationship with abdominal wall muscle tissue. Indeed, the Nijmegen questionnaire may be defined as a self-reported tool in order to register the degree of respiratory distress or hyperventilation $[12,27,28]$.

\subsection{Ultrasound Imaging of the Abdominal Wall}

All evaluations were carried out by a single operator (J.A.P.), a specialized physical therapist with 3 years of RUSI experience. The evaluator was not blinded to both groups during data evaluation [12]. A diagnostic ultrasound tool (Toshiba Aplio 500 Platinum; Toshiba American Medical Systems, Tustin, CA, USA) with a 7-14 MHz range linear transducer (18L7 PLT-1204BT type; $40 \mathrm{~mm}$ footprint) was used for B mode ultrasound imaging. According to the protocol of Whittaker et al. [12], ultrasound images of the EO, IO, and TrAb muscles were carried out with the subjects in supine position, with a cross-reference point placed between the iliac crest and the inferior border of subcostal line and the midaxillary line (Figures 1A and 2A); RA muscle was aligned with the umbilicus (Figures 1B and 2B); and IRD was measured just under the umbilicus (Figures $1 \mathrm{C}$ and 2C). Previously, anatomical landmarks were located by means of palpation and a dynamic ultrasound evaluation following the methodology proposed by Whittaker et al. [12], which showed excellent interday and interexaminer reliability (ICC $=0.92-0.99$ ) for these RUSI measurements. The mean of 3 repeated values was collected for each measurement at the end of expiration, maintaining the transducer at the same point and with the same pressure (only the pressure generated by the weight of the transducer). IRD was only evaluated in the midline. The rest of the measurements were obtained at the left and right sides. Muscle thickness was measured at the center on the image and considered as the distance $(\mathrm{cm})$ between the inside caliper lines of each muscle border. EO thickness was perpendicularly 
measured inside the superficial connective tissue and the connective tissue located between EO and IO. IO thickness was perpendicularly measured inside the connective tissue located between EO and $\mathrm{IO}$ and between $\mathrm{IO}$ and $\mathrm{Tr} \mathrm{Ab}$. TrAb thickness was perpendicularly measured inside the deep connective tissue and the connective tissue located between IO and $\operatorname{Tr} \mathrm{Ab}$ (Figure 2A). RA thickness was perpendicularly measured inside the superficial and deep connective tissues (Figure 2B). IRD was described as the horizontal distance between both RA muscles (Figure 2C) [12]. ImageJ software (version 2.0; US National Institutes of Health, Bethesda, MD, USA) was employed to measure all the images offline [28].
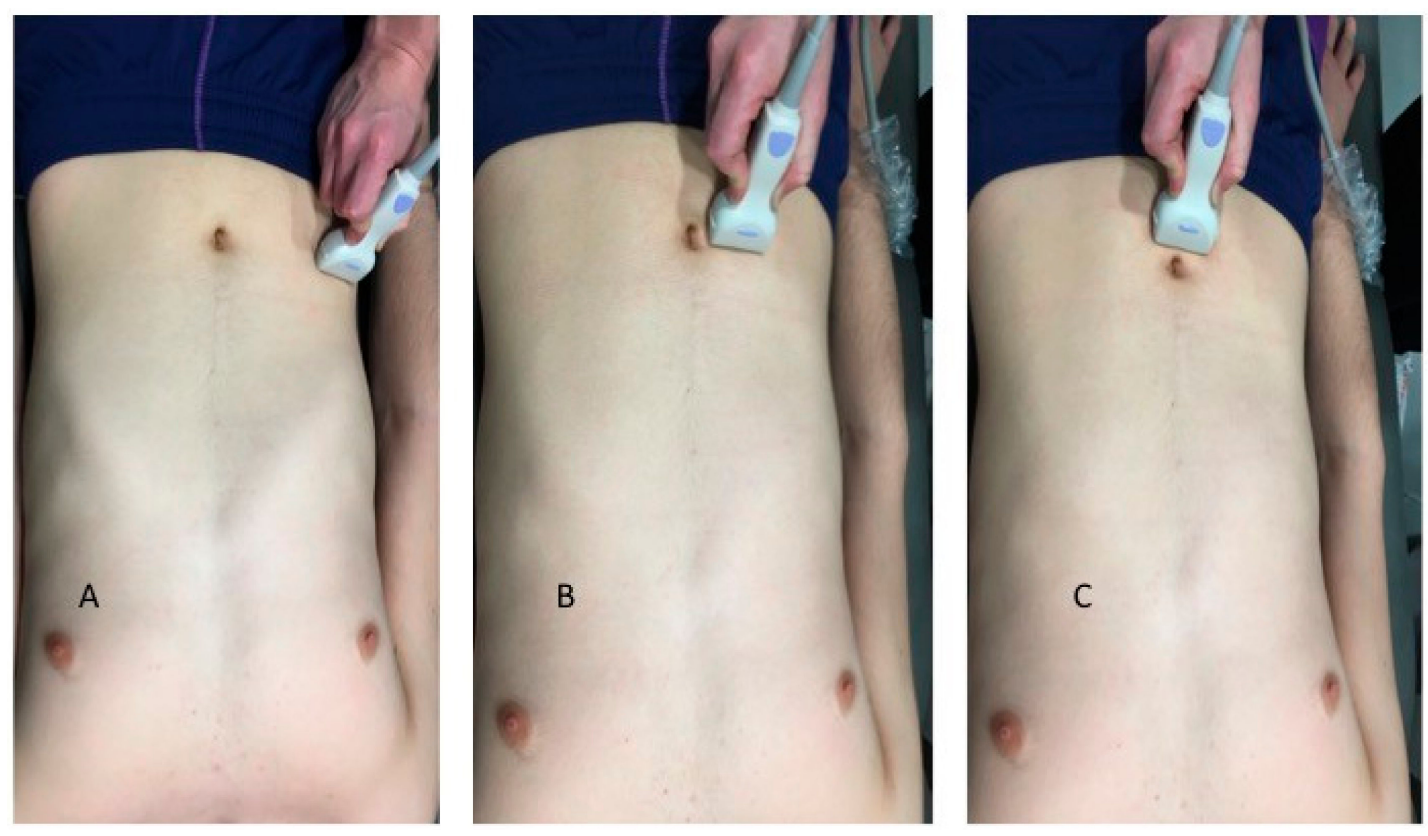

Figure 1. Transducer placement during ultrasound evaluation of the abdominal wall.
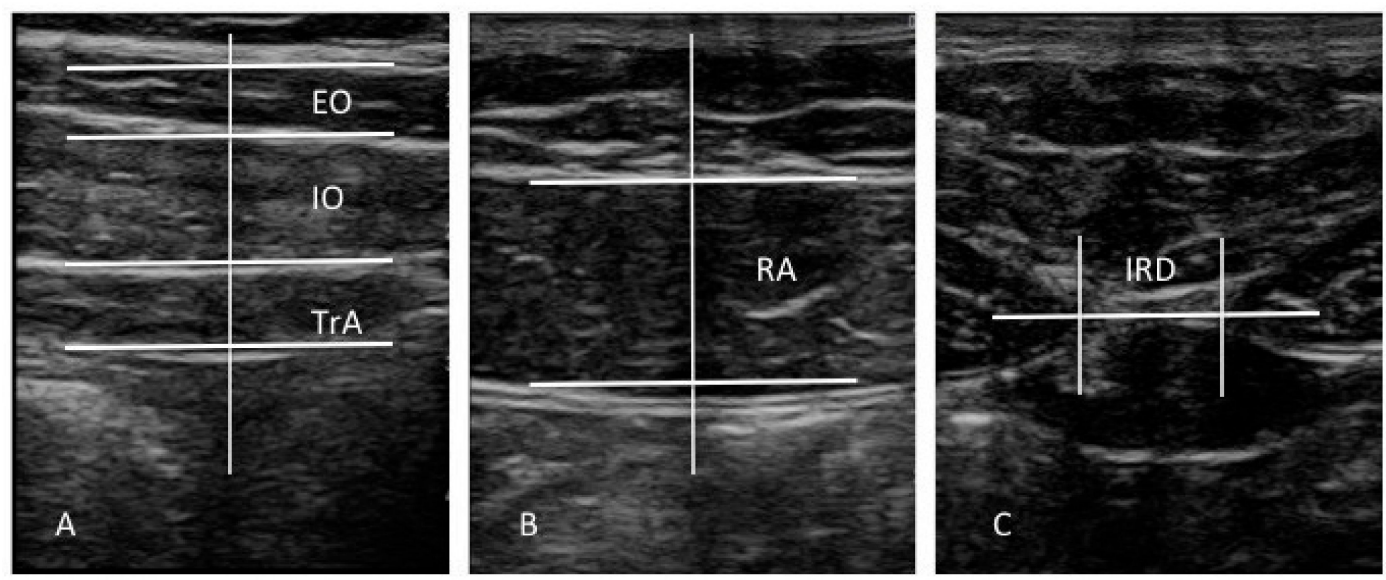

Figure 2. Muscle thickness and IRD measurements of the abdominal wall. EO, external oblique; IO, internal oblique; IRD, interrecti distance; TrA, transversus abdominis; RA, rectus abdominis.

\subsection{Statistical Analysis}

SPSS 22.0 software (IBM SPSS Statistics for Windows, IBM Corp., Armonk, NY, USA) was used to analyze the data. An $\alpha$ error of 0.05 (95\% confidence interval) and a desired power of $80 \%$ ( $\beta$ error of 0.2) were used. First, the Shapiro-Wilk test was utilized to assess normality. Second, a descriptive analysis was carried out for the total sample together, as well as both groups separately. Finally, 
a comparative analysis between both groups was performed. Considering the normality analysis of the total sample together, the student $t$-test for independent samples was applied for the parametric data and the Mann-Whitney $U$ test was used for the nonparametric data. Considering the normality analysis for both groups separately, mean \pm standard deviation (SD) was used to describe parametric data and the median \pm interquartile range (IR) was utilized to describe nonparametric data.

Moreover, a multivariate prediction was carried out by linear regression analysis in order to predict the statistically significant RUSI measurements of the abdominal wall. Linear regression analysis was performed following the stepwise selection method, using the $R^{2}$ coefficient to establish the quality adjustment. Demographic and descriptive data, including age, sex, weight, height, BMI, and Nijmegen questionnaire respiratory distress scores, were used as dependent variables. The between-group statistically significant differences of RUSI measurements of the abdominal wall (IRD, right and left $\mathrm{EO}$, and left $\operatorname{Tr} \mathrm{Ab}$ ) were used as independent variables.

\section{Results}

Considering Table 1, sociodemographic data did not show statistically significant differences $(p>0.05)$ in age between the two groups. Nevertheless, statistically significant differences $(p<0.05)$ in terms of greater height, weight, and Nijmegen scores were shown in favor of the elite basketball players versus the amateur basketball players.

Table 1. Sociodemographic data and respiratory distress scores of the basketball players. $\ddagger$

\begin{tabular}{cccc}
\hline Data & Amateur $(\boldsymbol{n}=\mathbf{1 6})$ & Elite $(\boldsymbol{n}=\mathbf{1 6})$ & $p$-Value \\
\hline Age, $\mathrm{y}$ & $23.0 \pm 7.0^{\dagger}$ & $21.5 \pm 8.75^{\dagger}$ & $0.590^{\ddagger}$ \\
Weight, $\mathrm{kg}$ & $79.98 \pm 8.97^{*}$ & $93.56 \pm 15.24^{*}$ & $0.004^{* *}$ \\
Height, $\mathrm{m}$ & $1.83 \pm 0.07^{*}$ & $1.94 \pm 0.10^{*}$ & $0.002^{* *}$ \\
BMI, kg/m $\mathrm{m}^{*}$ & $21.89 \pm 2.03^{*}$ & $23.83 \pm 2.88^{*}$ & $0.036^{* *}$ \\
Nijmegen test & $2.0 \pm 2.76^{+}$ & $12.43 \pm 3.24^{*}$ & $<0.001^{\ddagger}$
\end{tabular}

* Mean \pm standard deviation (SD) was applied. ${ }^{* *}$ Student $t$-test for independent samples was performed. ${ }^{\dagger}$ Median \pm interquartile range (IR) was used. ${ }^{\ddagger}$ Mann-Whitney $U$ test was utilized.

Regarding Table 2, ultrasound measurements of the abdominal wall muscles showed statistically significant differences $(p<0.05)$ in IRD and increased left TrAb thickness as well as decreased right and left EO thickness in favor of the elite versus amateur basketball players. The rest of the measurements did not show any statistically significant differences $(p>0.05)$.

Table 2. Ultrasound imaging of the abdominal wall muscles.

\begin{tabular}{|c|c|c|c|}
\hline Measurement & Amateur $(n=16)$ * & Elite $(n=16) *$ & $p$-Value \\
\hline \multicolumn{4}{|l|}{ Distance $(\mathrm{cm})$} \\
\hline IRD & $1.03 \pm 0.41(0.58-1.96)$ * & $1.50 \pm 1.01(0.90-3.64) \dagger$ & $0.001 \ddagger$ \\
\hline \multicolumn{4}{|l|}{ Thickness (cm) } \\
\hline Right RA & $1.44 \pm 0.30(0.93-2.02$ * & $1.57 \pm 0.33(1.10-2.26)^{*}$ & 0.260 ** \\
\hline Right EO & $1.44 \pm 0.30(0.93-2.02$ * & $0.50 \pm 0.13(0.34-0.89)^{*}$ & $0.026^{* *}$ \\
\hline Right IO & $1.10 \pm 0.20(0.82-1.57$ * & $1.04 \pm 0.27(0.36-1.38)$ * & $0.484 * *$ \\
\hline Right $\operatorname{Tr} \mathrm{Ab}$ & $0.38 \pm 0.10(0.26-0.65) \dagger$ & $0.42 \pm 0.19(0.29-1.15)+$ & $0.149 \ddagger$ \\
\hline Left RA & $1.41 \pm 0.27(1.02-1.84) *$ & $1.54 \pm 0.36(1.06-2.37)$ * & $0.247^{* *}$ \\
\hline Left EO & $0.70 \pm 0.16(0.48-0.94) *$ & $0.51 \pm 0.14(0.30-0.89)^{*}$ & $0.002 * *$ \\
\hline Left IO & $1.13 \pm 0.20(0.87-1.47)$ * & $1.08 \pm 0.22(0.70-1.41)^{*}$ & $0.487^{* * *}$ \\
\hline Left $\operatorname{Tr} A b$ & $0.40 \pm 0.07(0.29-0.54)$ * & $0.47 \pm 0.09(0.31-0.65)$ * & $0.034^{* *}$ \\
\hline
\end{tabular}

EO, external oblique; IO, internal oblique; IRD, interrecti distance; RA, rectus anterior; TrAb, transversus abdominis. ${ }^{*}$ Mean \pm standard deviation (SD) (minimum-maximum) was applied. ${ }^{* *}$ Student $t$-test for independent samples was performed. ${ }^{\dagger}$ Median \pm interquartile range (IR) (minimum-maximum) was used. ${ }^{\ddagger}$ Mann-Whitney $U$ test was utilized. 
Regarding the multivariate regression analysis of the statistically significant differences of the abdominal wall RUSI measurements shown in Table 3, statistically significant differences $(p<0.05)$ in IRD as well as right and left $\mathrm{EO}$ and left TrAb thickness with a prediction model $R^{2}$ varied from 0.196 to 0.507 .

Table 3. Multivariate predictive analysis of between-group statistically significant rehabilitative ultrasound imaging (RUSI) changes of the abdominal wall.

\begin{tabular}{|c|c|c|c|}
\hline Parameter & Model & $R^{2}$ Change ${ }^{\dagger}$ & Model $R^{2}$ \\
\hline IRD (cm) & $\begin{array}{c}0.841 \\
+0.068 * \text { Nijmegen test }\end{array}$ & 0.322 & 0.322 \\
\hline Right EO (cm) & $\begin{array}{c}0.748 \\
-0.019 * \text { Nijmegen test }\end{array}$ & 0.196 & 0.196 \\
\hline Left $\operatorname{Tr} \mathrm{Ab}(\mathrm{cm})$ & $\begin{array}{c}0.773 \\
+0.025 * \text { BMI } \\
-0.005 * \text { height } \\
+0.007 * \text { Nijmegen test }\end{array}$ & $\begin{array}{l}0.219 \\
0.106 \\
0.157\end{array}$ & 0.482 \\
\hline Left EO $(\mathrm{cm})$ & $\begin{array}{c}-0.573 \\
+0.258^{*} \text { group } \\
+0.035 * \mathrm{BMI}\end{array}$ & $\begin{array}{l}0.286 \\
0.220\end{array}$ & 0.507 \\
\hline
\end{tabular}

EO, external oblique; IRD, interrecti distance; TrAb, transversus abdominis. ${ }^{*}$ Multiplay: $\mathrm{BMI}\left(\mathrm{kg} / \mathrm{m}^{2}\right)$; group (elite $=1$; amateur $=2)$; height $(\mathrm{cm})$; Nijmegen test (scores); weight $(\mathrm{kg}) .{ }^{\dagger} p$-value $<0.05$ with $95 \%$ confidence interval $(\mathrm{CI})$ is shown.

\section{Discussion}

This novel research provides useful information regarding the musculature of the abdominal wall at rest in elite versus nonelite basketball players. To date, this may be considered the first study to determine an ultrasonography comparison of the abdominal wall between professional and nonprofessional basketball players. Nevertheless, motor control RUSI evaluation of the abdominal and trunk muscles may be an important indicator to predict the risk of injury in professional football players $[21,28,29]$.

Although our sample was composed of healthy subjects, the only prior study of RUSI evaluation of the abdominal wall at rest with the same methodology was performed with non-athletic subjects with and without LPP [28]. The Nijmegen test obtained fourfold higher respiratory distress scores for the elite versus nonelite basketball players. These values coincide with the Nijmegen scores of subjects with and without LPP, according to Whittaker et al. [12]. Nevertheless, these scores did not reach the cutoff for hypocapnia or hyperventilation syndrome $[12,25]$. Furthermore, subjects with LPP exhibited a thinner rectus anterior, while our professional basketball players did not show differences. Nevertheless, lower IRD was shown for subjects with LPP than for elite basketball players [12].

The multivariate predictive analysis (Table 3 ) of the statistically significant differences in abdominal wall RUSI measurements show that IRD $\left(R^{2}=0.322\right)$ and right EO $\left(R^{2}=0.196\right)$ may only be predicted by the Nijmegen test, left $\mathrm{EO}\left(R^{2}=0.507\right)$ may be predicted by the group and BMI, and left $\operatorname{Tr} A b\left(R^{2}=0.482\right)$ may only be predicted by BMI, height, and Nijmegen test. The rest of the variables were excluded from the model, and some variables, such as weight and age, did not predict any measurement.

\section{Limitations}

Several limitations should be considered in the present study. First, the sample showed differences in height, weight, BMI, and Nijmegen scores and may influence the ultrasound measurements according to different categories of basketball players. Although we used the Nijmegen test to determine the degree of respiratory distress according to the methodology of Whittaker et al. [28], we recognize that the Nijmegen measurement tool could be inappropriately applied to this population, 
because exercise is a purposeful activity that may cause some signs of respiratory distress as the cardiovascular system is stressed. Despite our sample showing statistically significant differences in demographic characteristics and Nijmegen test, we carried out a linear regression analysis in order to predict the influence of these demographic variables in the statistically significant outcome measurements of abdominal wall ultrasound imaging. Furthermore, basketball players with conditions such as LPP were not studied, and this may be useful in future research [28]. Second, muscle contraction changes were not considered and could be interesting in RUSI evaluation during active straight leg raise test, abdominal hollowing or drawing-in maneuver, abdominal curl, Valsalva maneuver, or functional tasks [15,21,28-32]. Third, other ultrasonography modes, such as M-mode, and software analysis, such as sonoelastography, were not used and may be useful to study muscle tissue characteristics $[31,32]$. Finally, despite the previously reported reliability of RUSI abdominal wall measurements according to our procedure, within-sample reliability of our study was not verified, because we accurately followed the methodology of a prior study, which showed excellent reliability [12].

\section{Conclusions}

In conclusion, increased IRD and TrAb thickness and reduced EO thickness may be shown in elite versus amateur basketball players. Nevertheless, differences in demographic data and respiratory distress scores may predict these abdominal wall changes and should be considered in future RUSI studies of professional athletes.

Author Contributions: Carlos Romero-Morales, Jaime Almazán-Polo, Daniel López-López and César Calvo-Lobo conceived and designed the experiments; Carlos Romero-Morales, Jaime Almazán-Polo, Daniel López-López and César Calvo-Lobo performed the experiments; Carlos Romero-Morales, Jaime Almazán-Polo, Daniel López-López and César Calvo-Lobo analyzed the data; Carlos Romero-Morales, Jaime Almazán-Polo, David Rodríguez-Sanz, Patricia Palomo-López, Daniel López-López, Sergio Vázquez-González and César Calvo-Lobo contributed reagents/materials/analysis tools; Carlos Romero-Morales, Jaime Almazán-Polo, David Rodríguez-Sanz, Patricia Palomo-López, Daniel López-López, Sergio Vázquez-González and César Calvo-Lobo wrote the paper.

Conflicts of Interest: There are no conflicts of interest or source of funding.

\section{References}

1. Potter, C.L.; Cairns, M.C.; Stokes, M. Use of ultrasound imaging by physiotherapists: A pilot study to survey use, skills and training. Man. Ther. 2012, 17, 39-46. [CrossRef] [PubMed]

2. Teyhen, D.S. Rehabilitative ultrasound imaging: The roadmap ahead. J. Orthop. Sports Phys. Ther. 2007, 37, 431-433. [CrossRef] [PubMed]

3. Blume, C.; Wang, S.S. Comparison of changes in supraspinatus muscle thickness in persons with subacromial impingement syndrome and asymptomatic adults. Physiother. Theory Pract. 2014, 30, 544-551. [CrossRef] [PubMed]

4. Mohseny, B.; Nijhuis, T.H.; Hundepool, C.A.; Janssen, W.G.; Selles, R.W.; Coert, J.H. Ultrasonographic quantification of intrinsic hand muscle cross-sectional area; reliability and validity for predicting muscle strength. Arch. Phys. Med. Rehabil. 2015, 96, 845-853. [CrossRef] [PubMed]

5. Taniguchi, M.; Fukumoto, Y.; Kobayashi, M.; Kawasaki, T.; Maegawa, S.; Ibuki, S.; Ichihashi, N. Quantity and Quality of the Lower Extremity Muscles in Women with Knee Osteoarthritis. Ultrasound Med. Biol. 2015, 41, 2567-2574. [CrossRef] [PubMed]

6. Lobo, C.C.; Morales, C.R.; Sanz, D.R.; Corbalán, I.S.; Marín, A.G.; López, D.L. Ultrasonography Comparison of Peroneus Muscle Cross-sectional Area in Subjects With or Without Lateral Ankle Sprains. J. Manipulative Physiol. Ther. 2016, 39, 635-644. [CrossRef] [PubMed]

7. Lobo, C.C.; Marín, A.G.; Sanz, D.R.; López, D.L.; López, P.P.; Morales, C.R.; Corbalán, I.S. Ultrasound evaluation of intrinsic plantar muscles and fascia in hallux valgus: A case-control study. Medicine 2016, 95, e5243. [CrossRef] [PubMed]

8. Strini, P.J.; Strini, P.J.; Barbosa, T.d.S.; Gavião, M.B. Assessment of thickness and function of masticatory and cervical muscles in adults with and without temporomandibular disorders. Arch. Oral Biol. 2013, 58, 1100-1108. [CrossRef] [PubMed] 
9. Javanshir, K.; Rezasoltani, A.; Mohseni-Bandpei, M.A.; Amiri, M.; Ortega-Santiago, R.; Fernández-de-Las-Peñas, C. Ultrasound Assessment of Bilateral Longus Colli Muscles in Subjects with Chronic Bilateral Neck Pain. Am. J. Phys. Med. Rehabil. 2011, 90, 293-301. [CrossRef] [PubMed]

10. Javanshir, K.; Amiri, M.; Mohseni Bandpei, M.A.; De las Penas, C.F.; Rezasoltani, A. The effect of different exercise programs on cervical flexor muscles dimensions in patients with chronic neck pain. J. Back Musculoskelet. Rehabil. 2015, 28, 833-840. [CrossRef] [PubMed]

11. Kiesel, K.B.; Underwood, F.B.; Mattacola, C.G.; Matacolla, C.; Nitz, A.J.; Malone, T.R. A comparison of select trunk muscle thickness change between subjects with low back pain classified in the treatment-based classification system and asymptomatic controls. J. Orthop. Sports Phys. Ther. 2007, 37, 596-607. [CrossRef] [PubMed]

12. Whittaker, J.L.; Warner, M.B.; Stokes, M. Comparison of the Sonographic Features of the Abdominal Wall Muscles and Connective Tissues in Individuals With and Without Lumbopelvic Pain. J. Orthop. Sport. Phys. Ther. 2013, 43, 11-19. [CrossRef] [PubMed]

13. Brown, S.H.M.; Ward, S.R.; Cook, M.S.; Lieber, R.L. Architectural analysis of human abdominal wall muscles: Implications for mechanical function. Spine 2011, 36, 355-362. [CrossRef] [PubMed]

14. Rankin, G.; Stokes, M.; Newham, D.J. Abdominal muscle size and symmetry in normal subjects. Muscle Nerve 2006, 34, 320-326. [CrossRef] [PubMed]

15. Teyhen, D.S.; Gill, N.W.; Whittaker, J.L.; Henry, S.M.; Hides, J.A.; Hodges, P. Rehabilitative ultrasound imaging of the abdominal muscles. J. Orthop. Sports Phys. Ther. 2007, 37, 450-466. [CrossRef] [PubMed]

16. Hides, J.; Wilson, S.; Stanton, W.; McMahon, S.; Keto, H.; McMahon, K.; Bryant, M.; Richardson, C. An MRI Investigation Into the Function of the Transversus Abdominis Muscle During "Drawing-In" of the Abdominal Wall. Spine 2006, 31, E175-E178. [CrossRef] [PubMed]

17. Brown, S.H.M.; McGill, S.M. A comparison of ultrasound and electromyography measures of force and activation to examine the mechanics of abdominal wall contraction. Clin. Biomech. 2010, 25, 115-123. [CrossRef] [PubMed]

18. Ferreira, P.H.; Ferreira, M.L.; Nascimento, D.P.; Pinto, R.Z.; Franco, M.R.; Hodges, P.W. Discriminative and reliability analyses of ultrasound measurement of abdominal muscles recruitment. Man. Ther. 2011, 16, 463-469. [CrossRef] [PubMed]

19. John, E.K.; Beith, I.D. Can activity within the external abdominal oblique be measured using real-time ultrasound imaging? Clin. Biomech. 2007, 22, 972-979. [CrossRef] [PubMed]

20. Hides, J.A.; Stanton, W.R. Can Motor Control Training Lower the Risk of Injury for Professional Football Players? Med. Sci. Sport. Exerc. 2014, 46, 762-768. [CrossRef] [PubMed]

21. Martin, C.; Olivier, B.; Benjamin, N. Asymmetrical abdominal muscle morphometry is present in injury free adolescent cricket pace bowlers: A prospective observational study. Phys. Ther. Sport 2017, 28, 34-42. [CrossRef] [PubMed]

22. White, R.G.; Hakim, A.J.; Salganik, M.J.; Spiller, M.W.; Johnston, L.G.; Kerr, L.; Kendall, C.; Drake, A.; Wilson, D.; Orroth, K.; et al. Strengthening the Reporting of Observational Studies in Epidemiology for respondent-driven sampling studies: "STROBE-RDS" statement. J. Clin. Epidemiol. 2015, 68, 1463-1471. [CrossRef] [PubMed]

23. Whittaker, J.L. Ultrasound imaging of the lateral abdominal wall muscles in individuals with lumbopelvic pain and signs of concurrent hypocapnia. Man. Ther. 2008, 13, 404-410. [CrossRef] [PubMed]

24. van Dixhoorn, J.; Duivenvoorden, H.J. Efficacy of Nijmegen Questionnaire in recognition of the hyperventilation syndrome. J. Psychosom. Res. 1985, 29, 199-206. [CrossRef]

25. Holt, G.R. Declaration of Helsinki-The World's Document of Conscience and Responsibility. South. Med. J. 2014, 107, 407. [CrossRef] [PubMed]

26. Schneider, C.A.; Rasband, W.S.; Eliceiri, K.W. NIH Image to ImageJ: 25 years of image analysis. Nat. Methods 2012, 9, 671-675. [CrossRef] [PubMed]

27. Hides, J.A.; Stanton, W.R.; Mendis, M.D.; Franettovich Smith, M.M.; Sexton, M.J. Small Multifidus Muscle Size Predicts Football Injuries. Orthop. J. Sport. Med. 2014, 2, 232596711453758. [CrossRef] [PubMed]

28. Leung, F.T.; Mendis, M.D.; Stanton, W.R.; Hides, J.A. The relationship between the piriformis muscle, low back pain, lower limb injuries and motor control training among elite football players. J. Sci. Med. Sport 2015, 18, 407-411. [CrossRef] [PubMed] 
29. Mota, P.; Pascoal, A.G.; Sancho, F.; Carita, A.I.; Bø, K. Reliability of the inter-rectus distance measured by palpation. Comparison of palpation and ultrasound measurements. Man. Ther. 2013, 18, 294-298. [CrossRef] [PubMed]

30. Bunce, S.M.; Hough, A.D.; Moore, A.P. Measurement of abdominal muscle thickness using M-mode ultrasound imaging during functional activities. Man. Ther. 2004, 9, 41-44. [CrossRef]

31. Ferreira, P.H.; Ferreira, M.L.; Hodges, P.W. Changes in recruitment of the abdominal muscles in people with low back pain: Ultrasound measurement of muscle activity. Spine 2004, 29, 2560-2566. [CrossRef] [PubMed]

32. Calvo-Lobo, C.; Diez-Vega, I.; Martínez-Pascual, B.; Fernández-Martínez, S.; de la Cueva-Reguera, M.; Garrosa-Martín, G.; Rodríguez-Sanz, D. Tensiomyography, sonoelastography, and mechanosensitivity differences between active, latent, and control low back myofascial trigger points. Medicine 2017, 96, e6287. [CrossRef] [PubMed]

(C) 2018 by the authors. Licensee MDPI, Basel, Switzerland. This article is an open access article distributed under the terms and conditions of the Creative Commons Attribution (CC BY) license (http:/ / creativecommons.org/licenses/by/4.0/). 